\title{
Illness insight and neurophysiological error-processing deficits in schizophrenia
}

\author{
Vinay Kansal ${ }^{\mathrm{a}}$ \\ Iulia Patriciu ${ }^{\mathrm{b}}$ \\ Michael Kiang ${ }^{\mathrm{a}, \mathrm{b}}$ \\ ${ }^{\mathrm{a} D e p a r t m e n t ~ o f ~ P s y c h i a t r y ~ a n d ~ B e h a v i o u r a l ~ N e u r o s c i e n c e s, ~ M c M a s t e r ~ U n i v e r s i t y, ~ H a m i l t o n, ~}$ \\ Ontario, Canada, L8S 4K1 \\ bSt. Joseph's Healthcare, Hamilton, Ontario, Canada, L8N 3K7
}

\author{
Corresponding Author (current address): \\ Michael Kiang, MD, PhD \\ Schizophrenia Division \\ Centre for Addiction and Mental Health \\ 250 College St. \\ Toronto, ON M5T 1R8 \\ Canada \\ Tel.: 1-416-535-8501 \\ Fax: 1-416-979-6936 \\ E-mail: michael.kiang@camh.ca
}

Notice: This is the author's version of a work that was accepted for publication in Schizophrenia Research. Changes resulting from the publishing process, such as peer review, editing, corrections, structural formatting, and other quality control mechanisms may not be reflected in this document. Changes may have been made to this work since it was submitted for publication. A definitive version was subsequently published in Schizophrenia Research, 156(1):122-7, 2014 Jun. doi: 10.1016/j.schres.2014.03.023. (C) 2014. This manuscript version is made available under the CC-BY-NC-ND 4.0 license http://creativecommons.org/licenses/by-nc-nd/4.0/ 


\begin{abstract}
Impaired illness insight in schizophrenia is associated with non-adherence and worse outcomes. Schizophrenia patients also exhibit error-monitoring deficits, which have been proposed to cause poor insight. To test this hypothesis, we examined whether schizophrenia patients' deficits in neurophysiological error-monitoring indices, the error-related negativity (ERN) and error positivity (Pe) event-related potential (ERP) amplitudes, are associated with impaired insight. ERPs were recorded in 18 schizophrenia patients and 18 normal comparison participants during a Stroop task. Patients' subnormal ERN and Pe amplitudes did not correlate with insight, suggesting that impaired insight in schizophrenia stems from neurocognitive mechanisms other than deficient error monitoring.
\end{abstract}

Keywords: Schizophrenia; cognition; illness insight; error processing; event-related potentials; electrophysiology; neurophysiology; error-related negativity; error positivity. 


\section{Introduction}

In schizophrenia, insight into having a mental illness and its symptoms is variable, and at least partially lacking in approximately 50\% of patients (Lincoln et al., 2007). Deficient insight in schizophrenia correlates only modestly with symptom severity, which accounts for 3-7\% of variance in insight (Mintz and Dobson, 2003). This dissociation suggests that insight is a "core and enduring deficit" of schizophrenia (Buckley et al., 2007) semi-independent from other symptoms. Poor insight is associated with decreased treatment adherence (Beck et al., 2011) and predicts worse outcomes (Drake et al., 2007; Lincoln et al., 2007). Thus, a better understanding of neurophysiological and cognitive mechanisms of poor insight in schizophrenia may help improve patient outcomes.

Researchers have hypothesized that deficits in error monitoring - i.e., monitoring one's thoughts and actions vis-à-vis external context and feedback - may contribute to poor insight in schizophrenia (Aleman et al., 2006; Drake and Lewis, 2003). Specifically, impaired ability to process information that counters hallucinations or delusions, or to recognize illogicality or inappropriateness in one's speech or behaviour, might contribute to lack of awareness of these symptoms.

Error monitoring can be probed at the neural level using scalp-recorded cognitive eventrelated brain potentials (ERPs). The error-related negativity (ERN) is an ERP waveform peaking approximately $50 \mathrm{~ms}$ after commission of an error in choice-response tasks (Gehring et al., 1993). Thus, it may index conflict between neural representations of the correct and incorrect responses as stimulus processing continues after an error (Yeung et al., 2004). Errors are also associated with a later, positive waveform, the error positivity (Pe), peaking between 200 and $400 \mathrm{~ms}$ after the incorrect response. ERN amplitude is similar regardless of whether the 
individual is consciously aware of the error; in contrast, the Pe is significantly larger when there is error awareness (Niewenhuis et al., 2001; Hughes and Yeung, 2011). These findings suggest that both preconscious error detection and conscious error awareness require processes reflected in the ERN, whereas conscious awareness also depends on processes indexed by the Pe. ERN amplitude is reduced in schizophrenia (Alain et al., 2002; Foti et al., 2012; Kopp and Rist, 1999; Mathalon et al., 2002; Morris et al., 2006; Morris et al., 2008; Perez et al., 2012), suggesting error-monitoring deficits. Pe amplitude has also been found to be reduced in schizophrenia in some (Foti et al., 2012; Perez et al., 2012) but not all studies (Alain et al., 2002; Horan et al., 2011; Kim et al., 2006; Mathalon et al., 2002; Morris et al., 2006; Simmonite et al., 2012).

As the relationship between neurophysiological error-monitoring deficits and impaired insight in schizophrenia has not previously been examined, we tested for an association between these variables, using the ERN and Pe as neurophysiological probes of deficient error monitoring. We hypothesized that, consistent with previous work, schizophrenia patients would exhibit reduced ERN and Pe amplitudes; and that both these abnormalities would be associated with poorer illness insight, consistent with a role for deficient conscious error recognition in the pathogenesis of impaired insight.

\section{Methods}

\subsection{Participants}

Participants included 18 outpatients with schizophrenia and 18 normal comparison participants (NCPs). Patients were recruited in Hamilton, Ontario, Canada from two outpatient clinics specializing in schizophrenia treatment and rehabilitation. NCPs were recruited from the community by advertising online, in local newspapers, and on bulletin boards. All participants 
gave informed written consent. The protocol was approved by the St. Joseph's Healthcare Hamilton Research Ethics Board.

Participants were screened diagnostically with the Mini International Neuropsychiatric Interview (MINI; Sheehan et al., 1998). DSM-IV diagnoses were established using a bestestimate approach based on the MINI and information from medical records and clinician reports. Exclusion criteria included: current manic or depressive episode, lifetime substance dependence, substance abuse in the past six months, and lifetime self-reported neurological disorder. NCPs were also excluded if they met criteria for any other Axis I diagnoses, or were taking psychotropic medication. Group demographic characteristics are shown in Table 1. Patient and control groups did not differ significantly on age, sex, or parental socioeconomic status.

\subsection{Clinical ratings}

Patients were rated on schizophrenia symptoms using the Scale for Assessment of Positive Symptoms (SAPS; Andreasen, 1984b), and Scale for Assessment of Negative Symptoms (SANS; Andreasen, 1984a). Symptoms were rated for the present, and for a past period of acute illness (e.g., period preceding the most recent hospitalization). From these ratings, we derived scores for Psychotic, Disorganized, and Negative symptom factors (Miller et al., 1993).

To assess insight, patients were administered the Scale to assess Unawareness of a Mental Disorder (SUMD; Amador et al., 1993). For the present and past periods identified while administering the SAPS and SANS, for any symptoms identified with these scales, patients were rated on awareness of the symptom, and degree to which they attributed it to a mental disorder. For each period, the average of awareness and attribution ratings for these symptoms was 
computed, yielding overall scores for present and past awareness and attribution. Higher scores indicate lower levels of insight.

Patients' clinical ratings are summarized in Table 2.

\subsection{ERP assessment}

ERPs were recorded while participants performed a Stroop task, with stimuli similar to those of Hajcak and Simons (2002). On each trial, participants were presented one of three colour words ('RED', 'GREEN', 'BLUE') in red or green font on a black background. A fixation mark was presented before each word. Words were presented for $200 \mathrm{~ms}$ at random stimulus-onset asynchronies between 2000 and 2400 ms. Participants pressed one of two keys on a response pad with either their right or left thumb, corresponding to the font color (red or green) of the presented word. Thus, there were congruent ('RED' in red, 'GREEN' in green), incongruent ('RED' in green, 'GREEN' in red), and neutral conditions ('BLUE' in red, 'BLUE' in green). Participants were asked to place equal emphasis on speed and accuracy. After completing a practice block of 48 trials, participants completed 4 blocks, each consisting of 32 trials of each type (congruent/red, congruent/green, incongruent/red, incongruent/green, neutral/red, neutral/green), for a total of 768 trials. Trials were presented in a fixed pseudorandomized order, which differed for each block.

ERPs were recorded in a sound-attenuated, electrically-shielded chamber. Participants were seated in a chair, $100 \mathrm{~cm}$ in front of a video monitor on which stimuli were presented, with each letter subtending on average $0.36^{\circ}$ of visual angle horizontally, and up to $0.55^{\circ}$ vertically. Continuous EEG was recorded from 32 approximately equally spaced scalp sites, bandpassed at 0.01-100 Hz, continuously digitized at $512 \mathrm{~Hz}$, and re-referenced off-line to the mean of the mastoids. 
Averages of artifact-free ERP trials were calculated for each type of trial (correct and error) after subtraction of the $100 \mathrm{~ms}$ pre-stimulus baseline. Consistent with previous work (Foti et al., 2012; Horan et al., 2011), ERN amplitude was measured as mean voltage at $\mathrm{Cz}$ from 0-100 ms post-response of the difference waveform obtained by subtracting the ERP average for error trials from the average for correct trials; and Pe amplitude was measured as mean voltage at $\mathrm{Pz}$ of the difference waveform from 200-400 ms post-response.

\subsection{Statistical analyses}

Correct response rates on the experimental task were analyzed in an ANOVA with Group (schizophrenia vs. NCP) as between-subjects factor, and stimulus type (congruent vs. incongruent vs. neutral) as within-subjects factor with Greenhouse-Geisser Epsilon correction. Reaction times were analyzed in an ANOVA with Group (schizophrenia vs. NCP) as betweensubjects factor and response type (correct vs. error) as within-subjects factor.

ERN and Pe amplitudes of patients versus NCPs were compared via independent-samples $t$ tests.

To examine whether ERN or Pe amplitude deficits were associated with poorer insight, across patients pairwise Pearson's correlations $r$ were computed for ERN and Pe amplitudes versus SUMD current unawareness, past unawareness, current misattribution, and past misattribution scores.

All $p$-values are two-tailed.

\section{Results}

\subsection{Behavioral data}


Mean task accuracy and response times (RTs) for both groups are shown in Table 3. Accuracy did not differ significantly by Group $\left(F_{1,34}=2.96, p=0.09\right)$ or Stimulus Type $\left(F_{2,68}=2.51, p=0.12\right)$, and there was no Group $\mathrm{x}$ Stimulus Type interaction $\left(F_{2,68}=1.18, p=0.28\right)$. RTs were faster for NCPs than for patients $\left(F_{1,34}=5.25, p=0.03\right)$, but there was no significant effect of Response Type $\left(F_{1,34}=3.35, p=0.08\right)$ or Group x Response Type interaction $\left(F_{1,34}=0.03\right.$, $p=0.86)$.

\subsection{Grand average ERPs}

Grand average ERPs for schizophrenia and NCP groups are shown at all electrodes in Figures $1 \mathrm{a}$ and $1 \mathrm{~b}$, respectively.

Mean ERN and Pe amplitudes for each group are shown in Figure 2. ERN amplitudes were smaller (less negative) in schizophrenia patients versus NCPs [-2.09 $\mu \mathrm{V}$ vs. $-6.45 \mu \mathrm{V}$; $t(34)=2.72 ; p=0.03]$. Pe amplitudes were smaller (less positive) in schizophrenia patients versus NCPs [3.22 $\mu \mathrm{V}$ vs. $9.16 \mu \mathrm{V} ; t(34)=-3.21 ; p=0.003]$.

\subsection{Correlations of ERN and Pe amplitudes with insight}

Table 4 shows correlations of patients' ERN and Pe amplitudes with insight scores and SAPS/SANS factor scores. For the ERN and SUMD, positive correlations indicate an association between lower insight (higher SUMD scores) and error processing deficits (less negative ERN amplitude). For the Pe and SUMD, negative correlations indicate an association between lower insight (higher SUMD scores) and error processing deficits (less positive ERN amplitudes). None of the correlations were significant (all $p>0.24$ ).

\section{Discussion}


We investigated whether impaired illness insight in schizophrenia is associated with errorprocessing deficits at the neurophysiological level. Specifically, we examined whether schizophrenia patients' deficits in two ERP indices of error monitoring, the ERN and Pe amplitudes, were associated with poor insight as assessed using the SUMD. Such an association would be consistent with the hypothesis that abnormal error monitoring contributes to illness insight in schizophrenia.

Consistent with previous findings, schizophrenia patients exhibited smaller than normal ERNs. We also found reduced Pe amplitudes in schizophrenia patients, adding to previous evidence for this abnormality (Foti et al., 2012; Perez et al., 2012). Although some other studies have not corroborated these findings (Alain et al., 2002; Horan et al., 2011; Kim et al., 2006; Mathalon et al., 2002; Morris et al., 2006; Simmonite et al., 2012), these contrasting results may be due to smaller sample sizes (Alain et al., 2002); higher-frequency cutoffs (1-2 Hz) in highpass filtering of ERP data (Kim et al., 2006; Morris et al., 2006); or task differences.

Contrary to our hypothesis, we found that neither ERN nor Pe reductions in our patient sample were associated with impaired insight into illness. These results suggest that unawareness of illness in schizophrenia is not related to deficits in error-monitoring processes reflected in the ERN and Pe, but arises instead from other cognitive mechanisms. Deficits in a number of other cognitive domains have been found to correlate independently with impaired insight in schizophrenia. These domains include working and long-term memory, and set-shifting (Nair et al., 2014), which may all be necessary for reflectively analyzing beliefs in light of evidence; and theory of mind (Konstantakopoulos et al., 2014), which includes the ability to apprehend how one is perceived by others. Further research is needed to improve our understanding of whether and how these and other factors contribute to the pathogenesis of poor insight. 
Figure 1. Grand average ERPs time-locked to correct responses (black line) and error responses (red line), at all electrode sites, for: (a) schizophrenia patients, and (b) NCPs. Voltage is plotted in $\mu \mathrm{V}$ on the $y$-axis with negative plotted upward, and time is plotted in ms on the $x$-axis. Electrode sites $\mathrm{Cz}$ and $\mathrm{Pz}$, which were used for mean amplitude analyses for the ERN and Pe, respectively, are highlighted by boxes.

Figure 2: Bar plot of mean ERN and Pe amplitudes for schizophrenia patients and NCPs (error bars show standard deviations). 


\section{References}

Alain, C., McNeely, H. E., He, Y., Christensen, B. K., West, R., 2002. Neurophysiological evidence of error-monitoring deficits in patients with schizophrenia. Cereb. Cortex 12 (8), 840-846.

Aleman, A., Agrawal, N., Morgan, K. D., David, A. S., 2006. Insight in psychosis and neuropsychological function: meta-analysis. Br. J. Psychiatry 189, 204-212.

Amador, X. F., Strauss, D. H., Yale, S. A., Flaum, M. M., Endicott, J., Gorman, J. M., 1993. Assessment of insight in psychosis. Am. J. Psychiatry 150 (6), 873-879.

Andreasen, N.C., 1984a. Scale for the Assessment of Negative Symptoms. University of Iowa, Iowa City, IA.

Andreasen, N.C., 1984b. Scale for the Assessment of Positive Symptoms. University of Iowa, Iowa City, IA.

Beck, E. M., Cavelti, M., Kvrgic, S., Kleim, B., Vauth, R., 2011. Are we addressing the 'right stuff' to enhance adherence in schizophrenia? Understanding the role of insight and attitudes towards medication. Schizophr. Res. 132 (1), 42-49.

Blishen, B. R., Carroll, W. K., Moore, C., 1987. The 1981 socioeconomic index for occupations in Canada. Can. Rev. Sociol. Anthropol. 24, 465-488.

Buckley, P. F., Wirshing, D. A., Bhushan, P., Pierre, J. M., Resnick, S. A., Wirshing, W. C., 2007. Lack of insight in schizophrenia: impact on treatment adherence. CNS Drugs 21 (2), 129-141.

Drake, R. J., Dunn, G., Tarrier, N., Bentall, R. P., Haddock, G., Lewis, S. W., 2007. Insight as a predictor of the outcome of first-episode nonaffective psychosis in a prospective cohort study in England. J. Clin. Psychiatry 68 (1), 81-86. 
Drake, R., J., Lewis, S. W., 2003. Insight and neurocognition in schizophrenia. Schizophr. Res. $62(1-2), 165-173$.

Foti, D., Kotov, R., Bromet, E., Hajcak, G., 2012. Beyond the Broken Error-Related Negativity: Functional and Diagnostic Correlates of Error Processing in Psychosis. Biol. Psychiatry $71(10), 864-872$.

Gehring, W. J., Goss, B., Coles, M. G. H., Meyer, D. E., Donchin, E., 1993. A neural system for error detection and compensation. Psychol. Sci. 4 (6), 385-390.

Hajcak, G., and Simons, R. F., 2002. Error-related brain activity in obsessive-compulsive undergraduates. Psychiatry Res. 110 (1), 63-72.

Horan, W. P., Foti, D., Hajcak, G., Wynn, J. K., Green, M. F., 2011. Impaired neural response to internal but not external feedback in schizophrenia. Psychol. Med. 42 (8), 1637-1647.

Hughes, G., and Yeung, N., 2011. Dissociable correlates of response conflict and error awareness in error-related brain activity. Neuropsychologia 49 (3), 405-415.

Kim, M., Kang, S. S., Shin, K. S., Yoo, S. Y., Kim, Y. Y., Kwon, J. S., 2006. Neuropsychological correlates of error negativity and positivity in schizophrenia patients. Psychiatry Clin. Neurosci. 60 (3), 303-311.

Konstantakopoulos, G., Ploumpidis, D., Oulis, P., Patrikelis, P., Nikitopoulou, S., Papadimitriou, G. N., David, A. S., 2014. The relationship between insight and theory of mind in schizophrenia. Schizophr. Res. 152 (1), 217-222.

Kopp, B., Rist, F., 1999. An event-related brain potential substrate of disturbed response monitoring in paranoid schizophrenic patients. J. Abnorm. Psychol. 108 (2), 337-346. 
Lincoln, T. M., Lullmann, E., Rief, W., 2007. Correlates and long-term consequences of poor insight in patients with schizophrenia. A systematic review. Schizophr. Bull. 33 (6), $1324-1342$.

Mathalon, D. H., Fedor, M., Faustman, W. O., Gray, M., Askari, N., Ford, J. M., 2002. Response-monitoring dysfunction in schizophrenia: an event-related brain potential study. J. Abnorm. Psychol. 111 (1), 22-41.

Miller, D.D., Arndt, S., Andreasen, N.C., 1993. Alogia, attentional impairment, and inappropriate affect: their status in the dimensions of schizophrenia. Compr. Psychiatry 34 (4), 221-226.

Mintz, A. R., Dobson, K. S., Romney, D. M., 2003. Insight in schizophrenia: a meta-analysis. Schizophr. Res. 61 (1), 75-88.

Morris, S. E., Heerey, E. A., Gold, J. M., Holroyd, C. B., 2008. Learning-related changes in brain activity following errors and performance feedback in schizophrenia. Schizophr. Res. 99 (1-3), 274-285.

Morris, S. E., Yee, C. M., Nuechterlein, K. H., 2006. Electrophysiological analysis of error monitoring in schizophrenia. J. Abnorm. Psychol. 115 (2), 239-250.

Nair, A., Palmer, E. C., Aleman, A., David, A. S., 2014. Relationship between cognition, clinical and cognitive insight in psychotic disorders: a review and meta-analysis. Schizophr. Res. $152(1), 191-200$.

Nieuwenhuis, S., Ridderinkhof, K. R., Blom, J., Band, G. P., Kok, A., 2001. Error-related brain potentials are differentially related to awareness of response errors: evidence from an antisaccade task. Psychophysiology 38 (5), 752-760. 
Oldfield, R. C., 1971. The assessment and analysis of handedness: the Edinburgh inventory. Neuropsychologia 9 (1), 97-113.

Perez, V. B., Ford, J. M., Roach, B. J., Woods, S. W., McGlashan, T. H., Srihari, V. H., et al., 2012. Error monitoring dysfunction across the illness course of schizophrenia. J. Abnorm. Psychol. 121 (2), 372-387.

Sheehan, D. V., Lecrubier, Y., Sheehan, K. H., Amorim, P., Janavs, J., Weiller, E., et al., 1998. The Mini-International Neuropsychiatric Interview (M.I.N.I.): the development and validation of a structured diagnostic psychiatric interview for DSM-IV and ICD-10. J. Clin. Psychiatry 59 (S20), 22-33.

Simmonite, M., Bates, A.T., Groom, M.J., Jackson, G.M., Hollis, C., Liddle, P.F., 2012. Error processing-associated event-related potentials in schizophrenia and unaffected siblings. Int. J. Psychophysiol. 84 (1), 74-79.

Yeung, N., Botvinick, M. M., Cohen, J. D., 2004. The neural basis of error detection: conflict monitoring and the error-related negativity. Psychol. Rev. 111 (4), 931-959. 
Table 1. Demographic characteristics of the study sample

\begin{tabular}{|c|c|c|c|c|}
\hline & \multicolumn{2}{|c|}{$\begin{array}{l}\text { Patients with } \\
\text { schizophrenia }(n=18)\end{array}$} & \multicolumn{2}{|c|}{ NCPs $(n=18)$} \\
\hline \multicolumn{5}{|l|}{ Sex } \\
\hline Female & \multicolumn{2}{|l|}{7} & \multicolumn{2}{|l|}{10} \\
\hline Male & \multicolumn{2}{|l|}{11} & \multicolumn{2}{|l|}{8} \\
\hline \multicolumn{5}{|l|}{ Handedness (Oldfield, 1971) } \\
\hline Right & \multicolumn{2}{|l|}{15} & \multicolumn{2}{|l|}{17} \\
\hline Left & \multicolumn{2}{|l|}{1} & \multicolumn{2}{|l|}{1} \\
\hline \multirow[t]{2}{*}{ Ambidextrous } & \multicolumn{2}{|l|}{2} & \multicolumn{2}{|l|}{0} \\
\hline & Mean & $S D$ & Mean & $S D$ \\
\hline Age (years) & 43.2 & 7.8 & 41.1 & 9.8 \\
\hline $\begin{array}{l}\text { Parental socioeconomic status (SES; Blishen } \\
\text { et al., 1987) }\end{array}$ & 42.6 & 8.2 & 42.8 & 13.0 \\
\hline Age at onset of illness (years) & 25.7 & 6.8 & - & - \\
\hline $\begin{array}{l}\text { Time elapsed since most recent } \\
\text { hospitalization (years) }\end{array}$ & 9.1 & 8.0 & - & - \\
\hline Number of previous hospitalizations & 5.6 & 3.6 & - & - \\
\hline
\end{tabular}


Table 2. Clinical characteristics of patients with schizophrenia $(n=18)$

\begin{tabular}{|l|l|l|l|}
\hline \multicolumn{2}{|l|}{} & Mean & SD \\
\hline \multicolumn{2}{|l|}{} \\
\hline SAPS total score & 4.2 & 4.3 \\
\hline SANS total score & \multicolumn{2}{l|}{8.9} & 4.0 \\
\hline SANS/SAPS-derived factor scores & \multicolumn{2}{l|}{} \\
\hline Psychotic & 3.0 & 3.3 \\
\hline Disorganized & 1.2 & 1.5 \\
\hline Negative & 5.8 & 2.3 \\
\hline \multicolumn{2}{|l|}{} & \\
\hline SUMD & \multicolumn{2}{l|}{} \\
\hline Current unawareness & 2.32 & 1.30 \\
\hline Past unawareness & 1.99 & 1.14 \\
\hline Current misattribution & 2.56 & 1.33 \\
\hline Past misattribution & 2.40 & 1.29 \\
\hline
\end{tabular}


Table 3. Accuracy and reaction time in the experimental task

\begin{tabular}{|c|l|l|l|l|l|}
\hline & \multicolumn{2}{|l|}{$\begin{array}{l}\text { Patients with } \\
\text { schizophrenia } \\
(n=18)\end{array}$} & $\begin{array}{l}\text { NCPs } \\
(\boldsymbol{n}=\mathbf{1 8})\end{array}$ & $\begin{array}{l}\text { Group } \\
\text { comparison }\end{array}$ \\
\hline & Mean & $S D$ & Mean & $S D$ & \\
\hline Overall accuracy (\%) & 92.2 & 11.9 & 97.1 & 2.4 & $t(34)=1.72$ \\
\hline Reaction time (ms) & \multicolumn{5}{|l|}{} \\
\hline Overall & 561 & 99 & 491 & 177 & $t(34)=1.46$ \\
\hline Correct & 564 & 102 & 492 & 179 & $t(34)=1.48$ \\
\hline Error & 518 & 129 & 437 & 90 & $t(34)=4.87^{a}$ \\
\hline
\end{tabular}

${ }^{a} p=0.03$ 
Figure 1a.
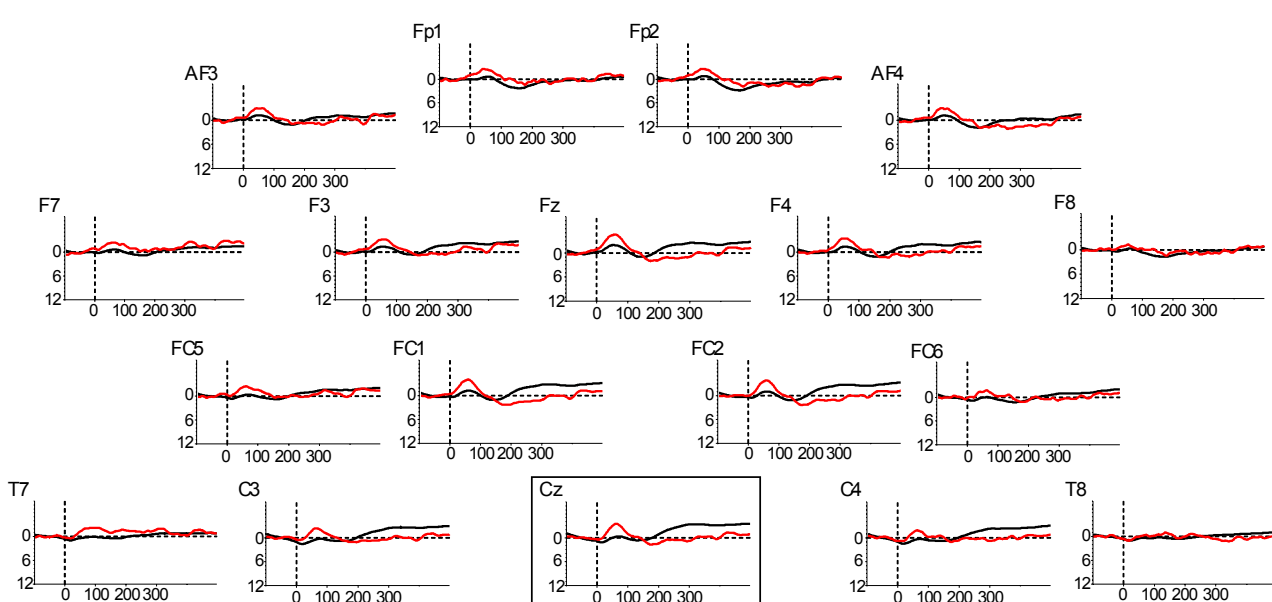

C
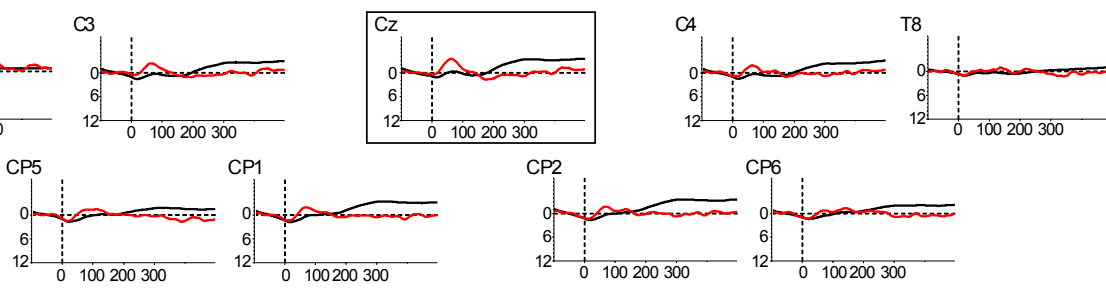

CP6
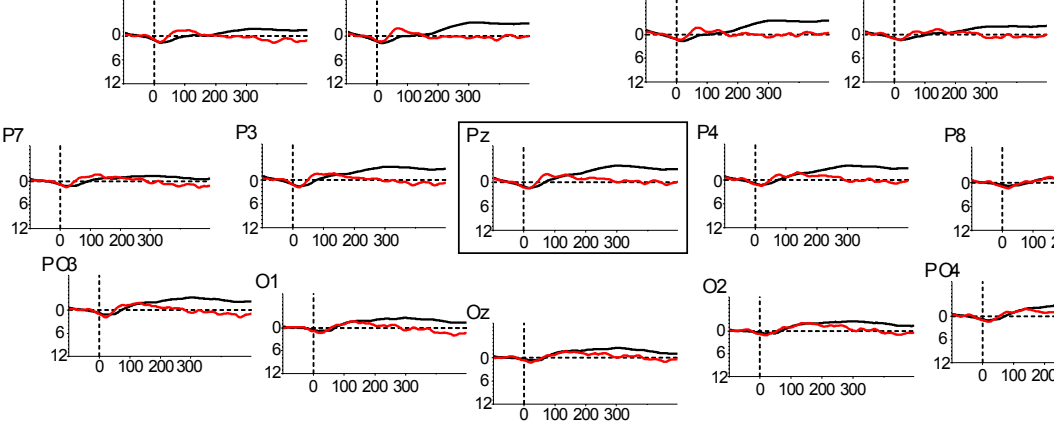

$\mathrm{PO}$
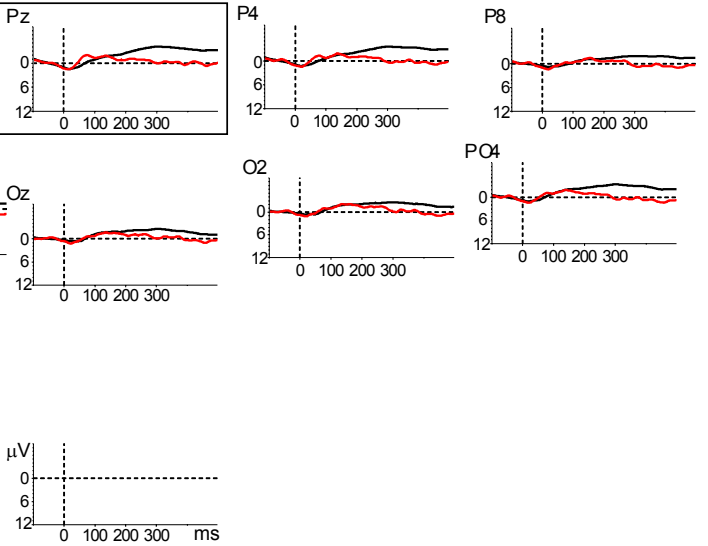
Figure 1b.

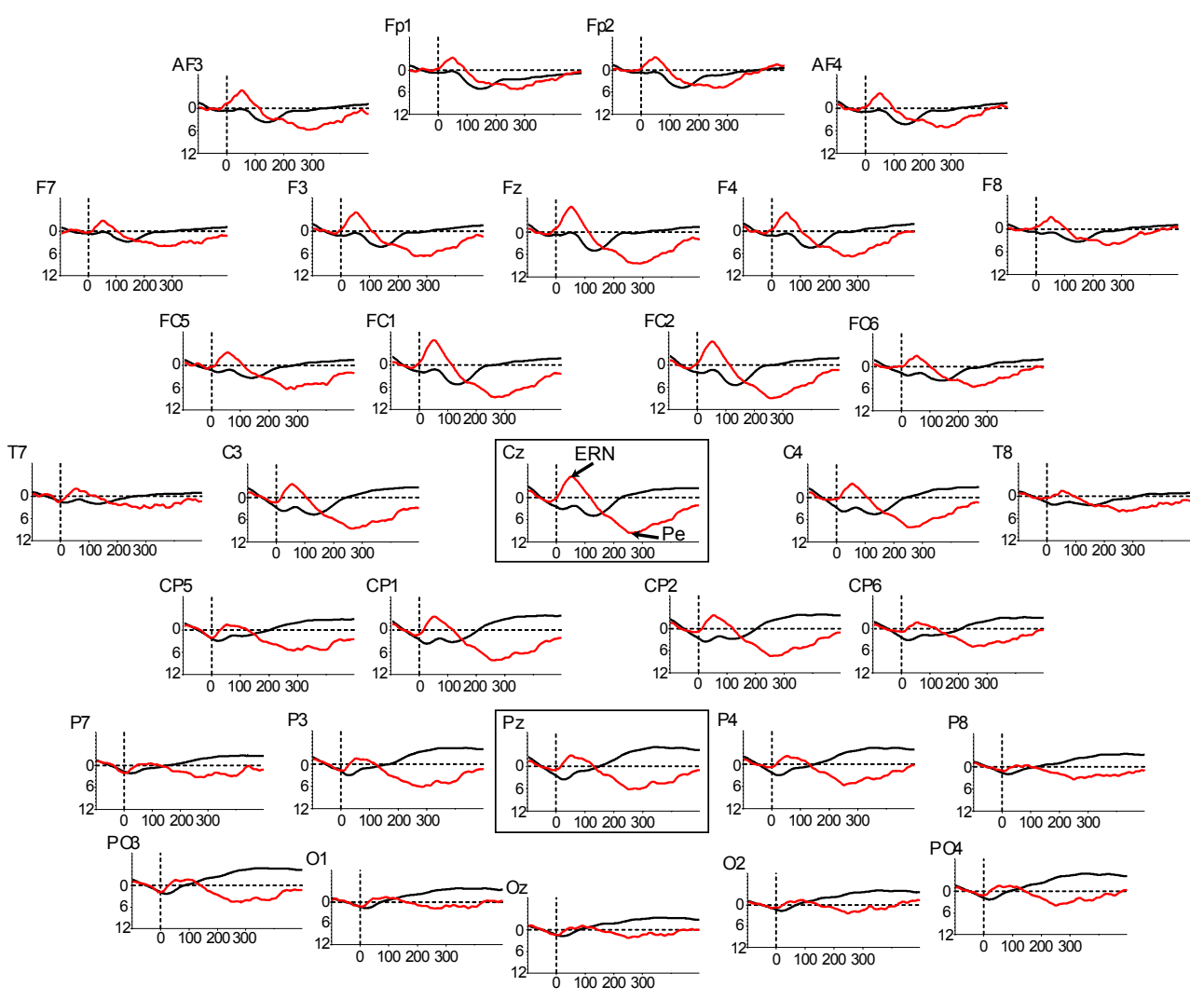

Error

Correct 
Figure 2.

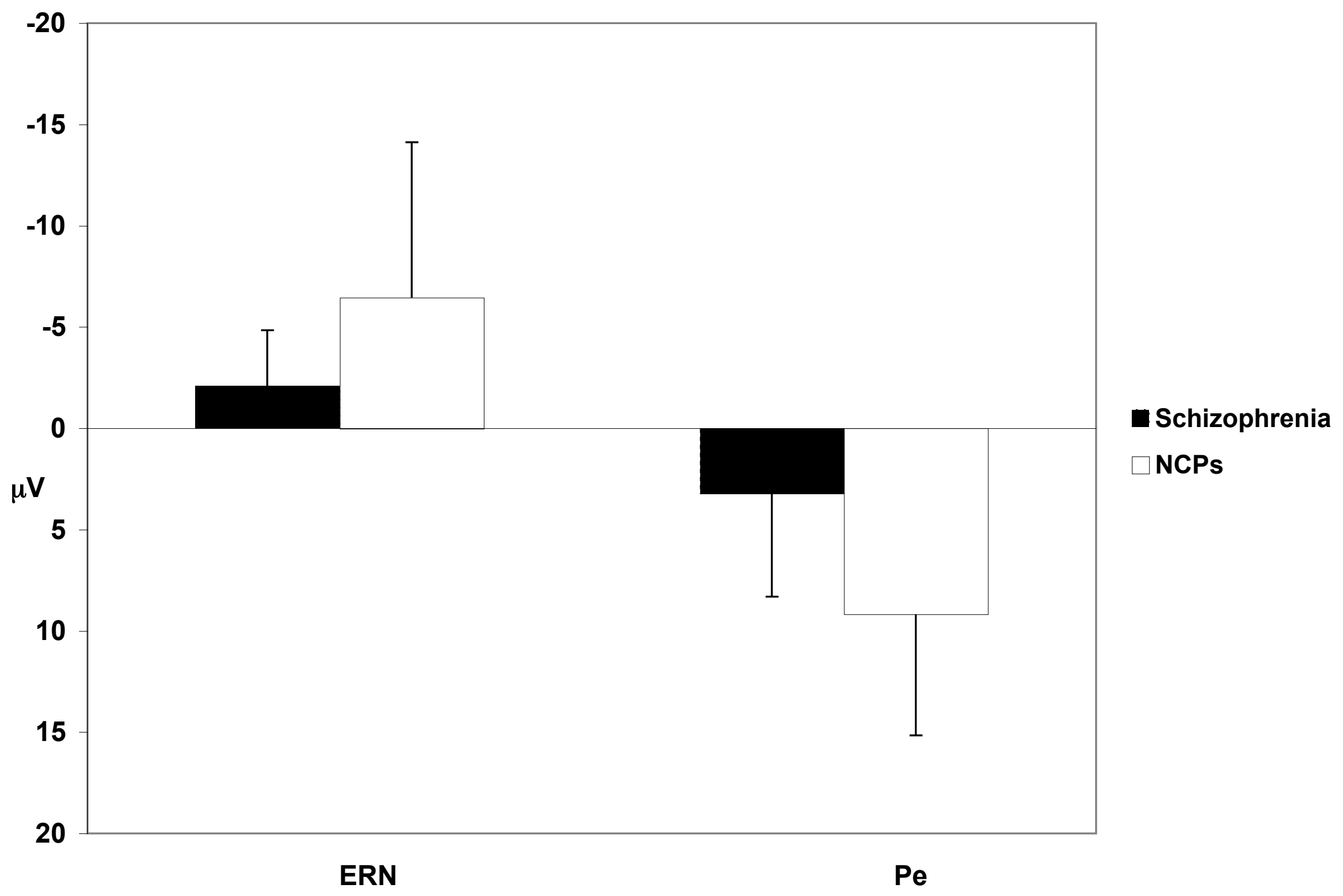

